\begin{tabular}{|l|l|}
\hline $\begin{array}{l}\text { Postprint Version } \\
\text { Journal website }\end{array}$ & 1.0 \\
& $\underline{\text { http://www2.bsl.nl/corp/common/framecreator.asp?ak=welkom\&ap=vakb\&altp }}$ \\
\hline Pubmed link & \\
\hline DOI &
\end{tabular}

This is a NIVEL certified Post Print, more info at http://www.nivel.eu

\title{
Forum: Onderzoek als product: uitzetten van onderzoek via inkoopprocedures
}

\author{
PETER P. GROENEWEGEN*
}

* NIVEL - Nederlands instituut voor onderzoek van de gezondheidszorg, Utrecht Prof. dr. P.P. Groenewegen, NIVEL, Utrecht, tel.030-2729665, e-mail: p.groenewegen@nivel.nl

Onderzoek zou een belangrijke rol moeten spelen in de vormgeving van beleid. 'Evidence-based policymaking' wordt dat genoemd. Uit deze term spreekt een optimistisch beeld van de manier waarop beleid tot stand komt. Beleidsprocessen zijn minder rationeel dan ze in betogen over evidence-based policy-making worden voorgesteld, en beleid en politieke beslissingen worden beïnvloed door veel meer overwegingen dan evidentie. ${ }^{1}$ Desalniettemin past gebruik van onderzoek in het beleid bij langere termijn processen van rationalisering in Westerse samenlevingen.

De zichtbaarheid van het gebruik van evidentie in beleid wordt bemoeilijkt doordat het gebruik van onderzoek kan variëren van instrumenteel gebruik om een concreet probleem op te lossen tot strategisch gebruik om een bepaald doel te bereiken (uitstel van besluitvorming, onderbouwing van een al gekozen positie et cetera) dat zich vaak niet verenigt met al te veel transparantie over dat gebruik. Daarnaast is er de bijdrage van onderzoek aan verheldering en ideeënvorming (de 'verlichtende' functie van onderzoek). De mogelijkheid om de evidentie te identificeren die ten grondslag ligt aan beleid verschilt dan ook voor deze drie vormen van gebruik en is het gemakkelijkst bij instrumenteel gebruik, bijvoorbeeld bij de toepassing van HTA onderzoek bij pakketbeslissingen. ${ }^{2} \mathrm{Er}$ is een zekere asymmetrie in de druk die wordt gelegd op onderzoekers om de maatschappelijke impact van hun onderzoek aan te tonen ${ }^{3-8}$ in vergelijking met de nadruk die op beleidsmakers wordt gelegd om de onderbouwing van hun beleid aan te tonen.

Toch hebben onderzoekers en beleidsmakers een gemeenschappelijk belang bij de kwaliteit van beleid en een optimaal gebruik van onderzoek in het beleidsproces. In dit artikel betoog ik dat de manier waarop onderzoek wordt uitgezet negatieve consequenties heeft voor de kans dat de resultaten worden gebruikt in het beleid. Steeds vaker wordt beleidsgericht onderzoek uitgezet via een inkoopprocedure. Als voordeel daarvan wordt gezien dat de inkopende partij over het algemeen meerdere aanbiedingen krijgt waaruit men de meest gunstige qua prijs en kwaliteit kan kiezen. Inkoopprocedures kunnen formeel zijn via een 'team inkoop', zoals in het geval van onderzoeksopdrachten van ministeries of daaraan gelieerde organisaties. Soms wordt een soortgelijke, maar minder streng gereguleerde aanpak gevolgd door andere organisaties. Het gaat over het algemeen om onderzoek dat een direct belang heeft voor de inkopende partij en dus moet leiden tot een toepasbaar 'product'. Echter, gegeven de kennis die we hebben over gebruik van onderzoek, is het de vraag of inkoopprocedures inderdaad leiden tot toepasbare kennis. ${ }^{9} \mathrm{Ik}$ zal deze vraag beantwoorden door kort in te gaan op voorwaarden voor de bruikbaarheid en het gebruik van onderzoek door de vragende partij, door de vraag te stellen wat voor soort relatie tussen potentiële gebruikers en onderzoekers daarvoor nodig is en ten slotte te bespreken hoe inkoopprocedures daarin passen.

\section{GEBRUIK VAN ONDERZOEK}

$\mathrm{Er}$ is in de loop van de jaren veel kennis opgebouwd over het gebruik van onderzoek. Het gaat dan om de voorwaarden waaronder de kans groter is dat onderzoek wordt gebruikt door belanghebbenden. ${ }^{10}$ Oudere opvattingen over de voorwaarden van het gebruik van onderzoek gaan alleen uit van verspreiding van de resultaten. Natuurlijk is dat een voorwaarde, maar belangrijker is dat de resultaten van onderzoek op de juiste tijd bij de juiste doelgroepen terechtkomen. Nieuwere opvattingen gaan ervan uit dat verspreiding 
alleen om verschillende redenen niet voldoende is. Ten eerste is het van belang dat de 'boodschap' zodanig wordt verpakt dat hij ook aankomt bij de doelgroep die er iets mee moet doen. Eén van de elementen daarin is een persoonlijke benadering van beoogde gebruikers van onderzoek. ${ }^{11}$ Daarbij kan de boodschap op maat bij de beoogde gebruikers worden gebracht en ontstaat de mogelijkheid onderling vertrouwen op te bouwen. Kortom, in deze opvatting wordt directe interactie tussen producenten van onderzoek en beoogde gebruikers gezien als een voorwaarde voor gebruik. 12 Een tweede belangrijk inzicht is dat deze interactie niet pas moet beginnen als het onderzoek af is maar ook heel belangrijk is in de fase waarin onderzoek tot stand komt. Het gaat niet alleen om beleidsmakers in hun rol van kennisgebruikers maar ook in de rol van kennisvragers. Naast onderzoekers die moeten investeren in het vertalen van beleidsvragen in onderzoek moeten beleidsmakers investeren in articulering van hun kennisbehoefte.

In onderstaand schema zijn verschillende interactiemomenten aangegeven. Het eerste ligt bij de transformatie van een probleem in de gezondheidszorg of in het beleid naar een onderzoekbare vraagstelling. Een probleem in de gezondheidszorg of een beleidsprobleem is niet zonder meer ook een onderzoeksprobleem. ${ }^{13}$ Een probleem in de sector is over het algemeen een complexe samenstelling van vragen met een empirisch karakter en normatieve elementen. ${ }^{14}$ Onderzoekers daarentegen willen deze complexiteit (in ieder geval in eerste instantie) verminderen om het probleem onderzoekbaar te maken en zoeken over het algemeen naar een waarden-neutrale aanpak. Er is een transformatie nodig van het probleem in de sector naar een onderzoekbare vraagstelling. Daarbij bestaat een levensgroot risico dat de vraagstelling die uiteindelijk onderzocht wordt in een proces van trechtering niet meer aansluit op het oorspronkelijke probleem in de sector. ${ }^{15}$ Daarom is interactie tussen de onderzoekers en de opdrachtgever in deze fase zo belangrijk.

\section{[FIGUUR 1]}

Interacties zijn daarnaast belangrijk in de fase waarin het onderzoek wordt uitgewerkt en natuurlijk in de slotfase wanneer de onderzoeksbevindingen weer getransformeerd worden naar beleidsimplicaties en oplossingen voor het probleem. Voor de vragen die hier centraal staan, is echter vooral de transformatie aan het begin van het proces van belang. Immers, daarin vindt de aanbesteding van onderzoek plaats.

\section{DE IDEALE RELATIE TUSSEN ONDERZOEK EN BELEID}

De ideale relatie tussen onderzoek en beleid vanuit het gezichtspunt van het gebruik van de onderzoekresultaten wordt gezien het voorafgaande gekenmerkt door veelvuldige interacties. Die interacties moeten in alle fasen van onderzoek plaats vinden. ${ }^{17}$ Daarbij moet worden geanticipeerd op hoe toekomstig gebruik ingepast kan worden in de institutionele structuren die sturend zijn bij de oplossing van het probleem in de sector. ${ }^{18}$ Voorbeelden van dergelijke institutionele structuren zijn:

- de manier waarop pakketbeslissingen tot stand komen; daarmee moet rekening worden gehouden bij onderzoek naar de introductie van nieuwe technologie in de gezondheidszorg binnen doelmatigheidsonderzoek. ${ }^{19}$

- de manier waarop beslissingsbevoegdheden en borging van verbeteringen in gezondheidszorgorganisaties zijn geregeld; dat is van belang bij de introductie van nieuwe organisatievormen in de zorg, zoals in vernieuwingsprogramma's als 'Sneller Beter ${ }^{20}$

- de beleidscyclus binnen de overheid; de fase in de beleidscyclus is van invloed op de informatiebehoefte en de bruikbaarheid van informatie bij de overheid. ${ }^{21}$

Interacties zouden op verschillende niveaus moeten plaats vinden; op het niveau van afzonderlijke projecten en op het niveau van programma's of instituten. De eerste resultaten van een EU-project waar voor Nederland de KNAW bij betrokken is, laten dat zien. Dit project spreekt in dit verband over 'productieve interacties' (www.siampi.eu). Interactie op het niveau van programma's of instituten maakt het mogelijk dat er niet alleen inter-persoonlijk vertrouwen ontstaat tussen onderzoekers en beleidsmakers, maar dat er ook inter-organisationeel vertrouwen ${ }^{22}$ ontstaat in de kennis en informatie die door een bepaald instituut wordt geleverd ('informatievertrouwen').

Bij grotere onderzoeksprogramma's waarbij volgende fasen afhankelijk zijn van de uitkomsten van eerdere fasen wordt wel gepleit voor interactief uitzetten van onderzoek. ${ }^{23}$ Daarbij gaan opdrachtgevers en onderzoekers een gezamenlijk commitment aan om over een langere periode onderzoek te doen. Over de 
invulling wordt op basis van uitkomsten een gezamenlijk plan gemaakt. Deze aanpak is sterk gebaseerd op vertrouwen en op voortdurende evaluatie van wat in eerdere fasen is bereikt.

\section{DE PASSENDHEID VAN INKOOPPROCEDURES}

Formele inkoopprocedures sluiten interactie over het algemeen uit. In de formele procedures moet alle communicatie via de inkoper lopen en is het onderzoekers niet toegestaan rechtstreeks contact op te nemen met de inhoudelijk deskundigen. 'Het is niet toegestaan andere functionarissen van Opdrachtgever rechtstreeks schriftelijk en/of mondeling te benaderen. Wanneer u dit toch doet, kan dit tot uitsluiting van deze opdracht leiden, daar in strijd met de algemene beginselen van het aanbestedingsrecht, als transparantie en non-discriminatie, wordt gehandeld' (citaat uit het hoofdstuk 'Procedurele voorschriften' bij een recente aanbesteding van het Ministerie van VWS).

Soms wordt een informatiesessie georganiseerd. Daarnaast bestaat de mogelijkheid vragen te stellen via email. De vragen en de antwoorden worden dan openbaar gemaakt en zijn dus beschikbaar voor alle potentiële indieners. 'De vragen en de daarbij behorende antwoorden worden middels een Nota van Inlichtingen geanonimiseerd naar alle aangeschreven contactpersonen gezonden' (citaat 'Procedurele voorschriften'). Er is echter geen dialoog en deelnemers aan informatiebijeenkomsten en stellers van vragen stellen zich strategisch op.

Het opstellen van het document dat de offertevraag beschrijft, vergt zodra het onderzoek maar enigszins complex wordt, veel onderzoekskennis van de opstellers. Die kennis is meestal niet voorhanden. Dat leidt tot (onder meer) de volgende problemen:

- De vragen die gesteld worden zijn te heterogeen. Ze beschrijven eerder een problematiek (met tal van aspecten waaronder normatieve) dan een onderzoekbare vraagstelling.

- De vragen verschillen sterk in hoeveel tijd en moeite die het kost om ze te beantwoorden en de opsteller van het offertedocument kan dat moeilijk beoordelen. Daardoor worden vragen gesteld waarvan het de vraag is of de betreffende organisatie ze niet net zo goed en sneller zelf (even) kan uitzoeken en vragen waar je met een onderzoeksprogramma van een tiental jaren misschien in de buurt van een antwoord kan komen.

- Daarmee samenhangend, de opsteller van het offertedocument moet een tamelijk gedetailleerd beeld van de te volgen aanpak van het onderzoek schetsen, maar mist daarvoor de kennis en ervaring.

Eén mogelijkheid om deze moeilijkheden te omzeilen is onderzoekers in te huren om de omschrijving van het project, de zogenoemde terms of reference, te laten opstellen. Nadeel daarvan is dat die onderzoekers zelf dan niet meer mogen meedingen in de procedures.

Deze problemen leiden tot slecht gespecificeerde offertedocumenten. Dat leidt tot vreemde processen die opgelost hadden kunnen worden als gekozen was voor een ander kader, namelijk een interactiekader, in plaats van een inkoopkader.

Slecht gedefinieerde offertedocumenten leiden ertoe dat de onderzoeksinstituten die een offerte indienen, te weinig of multi-interpretabele informatie hebben. Daardoor bestaat het gevaar dat de ingediende voorstellen te sterk uiteenlopen. In één geval leidde dat tot de volgende mededeling: 'De aangeboden voorstellen zijn zo divers dat we besloten hebben om alle partijen aanvullende vragen te stellen'. In een ander voorbeeld was de offerteprocedure feitelijk het begin van de vraagverheldering door de offertevragende organisatie. Twee organisaties die een klaarblijkelijk aansprekende offerte hadden opgesteld, werd gevraagd om eerst afzonderlijk en toen gezamenlijk in overleg te treden met de offertevrager. Op grond van die gesprekken is voor de offertevrager duidelijker geworden wat men nu precies wilde weten en wat de mogelijkheden voor onderzoek waren om daarin te voorzien. Daaruit is de vraag voortgekomen aan de twee onderzoeksinstituten om gezamenlijk een nieuw voorstel in te dienen.

Aan de ene kant is het dus belangrijk dat in de offertedocumenten een tamelijk gedetailleerde beschrijving van het onderzoek wordt gegeven. Daar staat tegenover dat bij een niet-adequate beschrijving de procedures vaak niet toestaan dat de onderzoekers zelf een alternatief formuleren: 'Inschrijver is niet vrij om naast deze inschrijving conform het bestek een variant aan te bieden' (citaat 'Procedurele voorschriften'). Een belangrijk aspect van de interactie tussen onderzoekers en beleidsmakers, namelijk het in overleg vaststellen wat een passend onderzoeksdesign is om een vraag te beantwoorden, wordt hiermee dus uitgesloten. 


\section{CONCLUSIES}

Inkoopprocedures passen niet bij belangrijke voorwaarden voor gebruik van onderzoek. Daar komen offertevragers lopende het proces soms ook achter en dan leidt een en ander alleen maar tot vertraging. Interacties tussen onderzoekers en potentiële gebruikers zijn van groot belang. Het RGO-advies over gezondheidszorgonderzoek beveelt dan ook aan om te zorgen voor systematische en niet-vrijblijvende interactie tussen onderzoekers en kennisgebruikers om het kennisgebruik te verbeteren. ${ }^{9} \mathrm{Nu}$ kan hiertegen worden ingebracht dat het instrument inkoop alleen wordt gebruikt bij eenvoudige onderzoeksopdrachten die goed te definiëren en te specificeren zijn door opdrachtgevers. In de praktijk worden ze daar echter niet toe beperkt en het onderscheid tussen eenvoudige onderzoeksopdrachten en meer complexe is moeilijk in zijn algemeenheid vast te leggen. Daarom is intensieve interactie vaak nodig om tot goede specificatie te komen.

Toch zijn we er met deze constateringen nog niet helemaal. Het uitzetten van onderzoek via inkoopprocedures is wellicht voor een deel voortgekomen uit het overplaatsen van werkbare procedures uit het ene domein naar een ander domein zonder dat er goed nagedacht is over de vraag of dat wel zinvol is. Daarnaast is het ook ten dele een reactie op nadelen verbonden aan interactieve uitzetten van onderzoek:

- te nauwe relaties tussen onderzoek en beleid brengen de onafhankelijkheid van onderzoek in gevaar. Er kan ongewenste beïnvloeding optreden en vermenging van verantwoordelijkheden. ${ }^{11}$

- gebrek aan uitdaging door concurrenten kan leiden tot een ongunstige prijs/kwaliteitsverhouding.

- nauwe relaties kunnen ook leiden tot afsluiting voor nieuwe toetreders.

Deze nadelen worden in de huidige situatie voor een deel opgelost door een intermediaire organisatie als ZonMw. Bij het tot stand komen van programma's doet ZonMw de vraagverheldering. Op projectniveau kijken commissies op basis van deskundigenoordelen naar relevantie en kwaliteit. Toch is er hierdoor een forse afstand van werkveld en beleid en gaan de procedures ten koste van de snelle respons die het beleid soms verlangt.

Een oplossingsrichting is om te komen tot een soort raamovereenkomsten waarbinnen dan meer specifieke onderzoeksopdrachten kunnen worden gedefinieerd. Zo'n raamovereenkomst kan tegemoet komen aan het belang van intensieve interactie en tegelijk rekening houden met genoemde nadelen. Binnen een langer lopende raamovereenkomst met een onderzoeksinstituut is sprake van een vorm van preferred providerschap die voor een bepaalde periode wordt afgesproken. Zo'n preferred providerschap zou tot stand moeten komen op basis van evaluatie van past performance waarna vertrouwen wordt geven voor een tevoren vastgestelde periode waarna evaluatie plaats vindt.

De huidige situatie is in ieder geval onbevredigend, zowel voor onderzoekers als voor opdrachtgevers. Onderzoek leent zich niet voor inkoopprocedures.

\section{NoOT}

Ik dank mijn collega's van het NIVEL en dr. Bert Boer (CVZ) voor hun commentaar op een eerdere versie van dit artikel

\section{LITERATUUR}

1. $\quad$ Black N. Evidence based policy: proceed with care. BMJ 2001;323:275-9.

2. Boer A. Onderzoek op maat: een verkenning van factoren voor het gebruik van Medical

Technology Assessment. Proefschrift. Rotterdam: EUR, 2002.

3. Buxton M, Hanney S. How can payback from health services research be assessed? J Health Serv Res Policy 1995;0:10-8.

4. KNAW. Societal impact of applied health research. Amsterdam: KNAW, 2002.

5. Ark G van, Klasen EC. Maatschappelijke impact van gezondheidsonderzoek. Tijdschr Gezondheidswet 2007;85:259-61.

6. Spaapen J, Dijstelbloem H, Wamelink F. Evaluating Research in Context: a method for comprehensive assessment. Den Haag: COS, 2007

7. Oortwijn WJ, Hanney SR, Ligtvoet A et al. Assessing the impact of health technology assessment in The Netherlands. Int J Technol Assess Health Care 2008;24:259-69.

8. ERiC. Handreiking Evaluatie van maatschappelijke relevantie van wetenschappelijk onderzoek. 2010, www.eric-project.nl 
Groenewegen, P.P. Onderzoek als product: uitzetten van onderzoek via inkoopprocedures. TSG: Tijdschrift voor Gezondheidswetenschappen: 2011, 89(4 forum), 206

9. RGO. Gezond zorgonderzoek: de toekomst van het gezondheidszorgonderzoek in Nederland. Den Haag: RGO, 2008.

10. Landry R, Amara N, Lamari M. Utilization of social science research knowledge in Canada. Res Policy 2001; 30: 333-349.

11. Innvaer S, Vist G, Trommald M, Oxman A. Health policy-makers' perceptions of their use of evidence: a systematic review. J Health Serv.Res.Policy 2002;7:239-44.

12. Huberman M. Research utilization: the state of the art. Int J Knowledge Transfer Utilization 1994; 7:13-33.

13. Ultee WC, Arts W, Flap HD. Sociologie: vragen, uitspraken, bevindingen. Groningen: WoltersNoordhoff, 2003 (par. 1.7: sociale problemen en sociologische problemen).

14. Wolters W, Graaf ND de. Maatschappelijke problemen: beschrijvingen en verklaringen. Meppel: Boom, 2005.

15. Klazinga NS, Plochg T. Gezondheidszorgonderzoek en de praktijk van beleid en zorgverlening. In: Plochg T, Juttman RE, Klazinga NS, Mackenbach JP (red). Handboek gezondheidszorgonderzoek. Houten: Bohn Stafleu van Loghum, 2007.

16. Bensing JM, Caris-Verhallen WMCM, Dekker J, Delnoij DMJ, Groenewegen PP. Doing the right thing and doing it right: toward a framework for assessing the policy relevance of health services research. Int J Technol Assess Health Care 2003;19:604-12.

17. Boer A. Gezond zorgonderzoek: in concreto. Tijdschr Gezondheidswet 2009;87:333-4.

18. Lavis J, Robertson D, Woodside JM, McLeod C, Abelson J, the Knowledge Transfer Study Group. How can research organizations more effectively transfer research knowledge to decision makers? Milbank Q 2003;81:221-47.

19. CVZ. Pakketbeheer in de praktijk. Diemen: College voor Zorgverzekeringen, 2006.

20. Dückers MLA, Stegeman I, Spreeuwenberg P, Wagner C, Sanders K, Groenewegen PP. Consensus on the leadership of hospital CEOs and its impact on the participation of physicians in improvement projects. Health Policy 2009; 91:306-13.

21. Hanney S, Gonzalez-Block MA, Buxton M, Kogan M. The utilisation of health research in policymaking: concepts, examples and methods of assessment. Health Res Policy Systems 2003;1:2.

22. Gulati R, Nickerson JA. Interorganizational Trust, Governance Choice, and Exchange Performance. Organ Sci 2008;19:668-708.

23. Lilford R, Jecock R, Shaw H, Chard J, Morrison B. Commissioning health services research: an iterative method. J Health Serv Res Policy 1999; 4:164-7. 
Groenewegen, P.P. Onderzoek als product: uitzetten van onderzoek via inkoopprocedures. TSG: Tijdschriłt voor Gezondheidswetenschappen: 2011, 89(4 forum), 206

\section{FIGUUR}

Figuur 1. Relatie tussen beleid/veld en onderzoek

Gezondheidszorg

(Beleids)probleem<smiles>[CH]C</smiles>

intermediaire groepen/stakeholders<smiles>[CH]C</smiles>

beleidsimplicaties oplossingen voor het probleem

\section{Onderzoek}

$\rightarrow \quad$ transformatie

$\rightarrow$

Onderzoeksvraagstelling hypothesen

passend uitvoerbaar

$\vec{\leftarrow}$

onderzoeksontwerp gegevensverzameling analyses

transformatie<smiles>[CH]=C</smiles>

conclusie 